\title{
O currículo de história na reforma da Secretaria Municipal de Educação do Rio de Janeiro
}

Caroline da Luz Moraes

Luisa Kaufman Spindola'

\begin{abstract}
Resumo
A proposta desse artigo é apresentar duas pesquisas que investigaram as mudanças realizadas no currículo de história da rede municipal do Rio de Janeiro, empreendidas pela gestão que atuou na Secretaria Municipal de Educação do Rio de Janeiro (SME/RJ) entre os anos de 2009 e 2013. Em busca da melhora da qualidade do ensino nas escolas, a SME/RJ iniciou uma reforma no currículo e no sistema de avaliação da rede, que incluiu a elaboração de Orientações curriculares e de Cadernos pedagógicos, no caso da disciplina escolar história. A primeira pesquisa foi realizada no contexto de produção dos Cadernos pedagógicos, a partir da atuação dos professores formuladores no trabalho de elaboração desse material. A segunda pesquisa investiga as modificações da política curricular realizadas por professores de história da rede que atuam no contexto da prática. 0 objetivo deste artigo é estabelecer um diálogo entre essas pesquisas, uma vez que ambas utilizaram como principal referencial teórico-metodológico, o ciclo de politicas (BOWE; BALL; GOLD, 1992). Considerando a complexidade das esferas da política, foi constatado que, ao circular pelos contextos estudados, a reforma curricular não foi simplesmente recebida e incorporada, mas modificada pelos sujeitos envolvidos, que produziram sentidos diferentes no texto original da política.
\end{abstract}

\section{Palavras-chave}

Currículo de história - Ciclo de políticas - Material didático de história.

I- Pontifícia Universidade Católica do Rio de Janeiro, Rio de janeiro, RJ, Brasil.

Contatos: carolinedaluzmoraes@gmail.com; lukaufman2000@yahoo.com.br 


\title{
History curriculum in the reform of Rio de Janeiro Municipal Department of Education
}

Caroline da Luz Moraes'

Luisa Kaufman Spindola"

\begin{abstract}
This article presents two studies on the changes in the history curriculum of the municipal education system of Rio de Janeiro, which were undertaken by Rio de Janeiro Municipal Department of Education from 2009 to 2013. In an attempt to improve the quality of teaching, the Education Department launched a reform in the curriculum and the assessment system of municipal schools, which included the creation of Orientações curriculares (Curriculum guidelines) and Cadernos pedagógicos (Pedagogical notebooks) in the case of the history discipline. The first study was conducted in the context of the making of Cadernos pedagógicos and based on the work of teachers involved in it. The second study investigated the changes made in the curriculum policy by history teachers who work in classrooms in the municipal system. The goal of this article is to establish a dialogue between the studies, since both used the cycle of policies (BOWE; BALL; GOLD, 1992) as their main theoretical-methodological framework. Considering the complexity of the spheres of the policy, we found that, as the curriculum reform circulated in the contexts studied, it was not simply received and incorporated, but modified by the subjects involved, who produced meanings which differ from the original text of the policy.
\end{abstract}

\section{Keywords}

History curriculum - Cycle of policies - History teaching materials.

I- Pontifícia Universidade Católica do Rio de Janeiro, Rio de janeiro, RJ, Brasil.

Contacts: carolinedaluzmoraes@gmail.com;

lukaufman2000@yahoo.com.br 


\section{Introdução}

Este artigo tem a intenção de apresentar duas pesquisas qualitativas que utilizaram o ciclo de politicas (BOWE; BALL; GOLD, 1992) como um dos referenciais teórico-metodológicos. As investigações foram desenvolvidas durante os anos de 2012 e 2013, vinculadas ao Grupo de Estudo Formação de Professores, Currículo e Cotidiano Escolar (GEFOCC), no programa de pós-graduação da Pontifícia Universidade Católica do Rio de Janeiro (PUC-Rio).

Os temas das pesquisas estão relacionados à política curricular empreendida durante 0 mandato da Secretária de Educação do município do Rio de Janeiro, Claudia Costin, quando uma nova política educacional foi elaborada, proporcionando mudanças no currículo das escolas. Essas mudanças aconteceram por meio da reorganização curricular e do sistema de avaliação, através da elaboração de Orientações curriculares, Cadernos pedagógicos, lista de descritores com habilidades a serem avaliadas a cada bimestre e avaliações unificadas para verificar os resultados da aprendizagem nas escolas.

Foi uma opção delimitar o campo investigado às propostas curriculares da disciplina história na rede municipal. Primeiramente, porque ambas as pesquisadoras são graduadas nessa área. Além disso, a análise demarcada em uma área de conhecimento específica possibilitou um melhor aprofundamento das questões levantadas, uma vez que se optou por uma pesquisa de caráter qualitativo, sendo utilizadas entrevistas como principal recurso metodológico (MINAYO, 2008). Com esse limite estabelecido, foi possivel dialogar com outros estudos da mesma temática, podendo contribuir com a produção de conhecimento no campo da educação.

A pesquisa 1 (SPINDOLA, 2014) esteve relacionada, mais diretamente, ao contexto de produção dos Cadernos pedagógicos de história da Secretaria Municipal de Educação do Rio de Janeiro (SME/RJ) a partir da atuação dos professores formuladores no trabalho de elaboração deste material. A pesquisa 2 (MORAES, 2012) investigou como professores de história da rede municipal do Rio de Janeiro reinterpretaram essa política curricular no contexto da prática, em vista de sua autonomia docente.

0 ciclo de políticas elaborado por Stephen Ball e colaboradores é um referencial analítico útil para a apreciação de programas e políticas educacionais e nos auxiliou a refletir sobre como os textos oficiais, no caso dessa política educacional, são estruturados e de que forma são implementados nos diferentes contextos. A elaboração do roteiro da entrevista teve como base a ficha sugerida por Mainardes (2006) para investigações que utilizam o ciclo de políticas como referencial teórico-metodológico.

\section{A política educacional da SME/RJ}

Em 2009, Eduardo Paes assumiu o cargo de prefeito da cidade do Rio de Janeiro e Claudia Costin foi escolhida como secretária municipal de Educação. Essa gestão iniciou uma série de mudanças no sistema de ensino, tendo como justificativa "dar um salto na qualidade da Educação no Rio de Janeiro". ${ }^{1}$

Segundo a secretária, a elaboração de um "currículo municipal único, claro, organizado por bimestre” (COSTIN, 2013) seria fundamental para que as demais iniciativas pedagógicas fossem criadas e para a garantia da qualidade esperada. Nas Orientações curriculares, são estabelecidos objetivos, conteúdos, habilidades e são feitas sugestões para serem desenvolvidas bimestralmente, durante o ano letivo, em cada disciplina escolar. Essa diretriz é destinada à educação infantil, ensino fundamental (primeiro e segundo segmentos) e ao programa de educação para jovens e adultos (PEJA). ${ }^{2}$

1- SECRETARIA MUNICIPAL DE EDUCAÇÃO DO RIO DE JANEIRO. Conheça a Secretaria. Disponivel em: <http://www.rio.rj.gov.br/web/sme/ exibeconteudo?article-id=94101>. Acesso em: 9 out. 2012.

2- As Orientações curriculares de história possuem apenas as listas com objetivos, conteúdos e habilidades e não apresentam sugestões de atividades. 
Os Cadernos pedagógicos, material desenvolvido pela Secretaria de Educação, são destinados à educação infantil, casa de alfabetização ( $1^{\circ}$ ao $3^{\circ}$ anos), às disciplinas língua portuguesa, matemática e ciências ( $4^{\circ}$ ao $9^{\circ}$ anos), história e geografia $\left(6^{\circ}\right.$ ao $9^{\circ}$ anos) e aos projetos Nenhuma Criança a Menos e Nenhum Jovem a Menos. Também foram produzidos Cadernos pedagógicos para atividades de férias e reforço escolar nas disciplinas língua portuguesa e matemática. Além disso, foram elaboradas aulas digitais para todas as disciplinas do $1^{\circ}$ ao $9^{\circ}$ anos, que são exibidas na Educopédia. ${ }^{3}$ Houve também o fortalecimento do sistema de reforço escolar e dos projetos de aceleração, na tentativa de reorganizar o fluxo escolar.

É importante ressaltar que, neste trabalho, os Cadernos pedagógicos, as Orientações curriculares e os descritores são considerados como o currículo oficial da rede municipal, os quais, junto com o sistema de avaliação, formam a política educacional assumida pela Secretaria de Educação. Como a disciplina história não realiza a avaliação bimestral unificada, esta não possui lista de descritores. Portanto, para essas pesquisas, utilizamos apenas as Orientações curriculares e os Cadernos pedagógicos.

Segundo Marcondes (2013, p. 137), a permanente busca pela qualidade no ensino público fundamental tem levado estados $\mathrm{e}$ municípios brasileiros a utilizar os chamados sistemas apostilados, orientações prescritivas para o trabalho dos professores, adotadas com o objetivo de direcionar a atividade docente, em busca de uma melhoria dos resultados dos alunos em testes padronizados, como a Prova Brasil e outras avaliações estaduais e municipais.

A utilização dos sistemas apostilados está relacionada à crença de que o currículo apostilado aproxima a escola pública da qualidade da escola privada, pois as apostilas

3- A Educopédia é uma plataforma online de aulas digitais, disponível para professores, alunos e visitantes. Disponivel em: <http://www.educopedia. com.br/>. Acesso em: 06 maio 2014. adquiridas são formuladas por empresas que possuem a reputação de uma trajetória bemsucedida, por conseguirem aprovar parte de seus alunos em cursos superiores de alta disputa no país. No entanto, como afirmam Adrião et al. (2009, p. 808), as apostilas oferecidas às escolas públicas são um material de menor custo, que não concorre com aquele das escolas privadas do município; caso contrário, poderia haver um êxodo de matrículas para o setor público, "estabelecendo-se, ineditamente, uma concorrência intra-serviços oferecidos pela mesma empresa”.

No caso da rede municipal do Rio de Janeiro, a própria SME/RJ é responsável pela elaboração do material didático, mantendo em seu quadro interno equipes para essa atividade.

As avaliações unificadas da rede municipal são compostas pela Prova Rio e as avaliações bimestrais. A Prova Rio é uma avaliação externa do rendimento escolar das disciplinas língua portuguesa e matemática, cujo objetivo é apontar a qualidade do ensino na rede municipal. A sua aplicação é anual nos $3^{\circ}, 4^{\circ}, 7^{\circ}, 8^{\circ}$ anos do ensino fundamental e a cada dois anos nos $5^{\circ}$ e $9^{\circ}$ anos. As avaliações bimestrais são aplicadas em todos os anos de escolaridade. No entanto, nas turmas de primeiro segmento, são realizadas avaliações de língua portuguesa e matemática; nas turmas de segundo segmento, são aferidas as disciplinas de língua portuguesa, matemática e ciências. Os resultados das provas unificadas formam mapas que mostram a evolução das escolas em cada disciplina, frente à média da rede.

Objetivando o "salto de qualidade" da educação, a Secretaria implementou também uma política de metas e premiação. As metas a serem atingidas pelas escolas são estipuladas de acordo com o Índice de Desenvolvimento da Educação no Município do Rio de Janeiro (Ide-Rio), que é medido a partir do desempenho da Prova Brasil, aliado ao índice de aprovação e evasão das escolas. Esse índice serve de parâmetro para a concessão do Prêmio Anual de Desempenho para os servidores das escolas da rede. 
Reformas políticas semelhantes são introduzidas atualmente em diversos países. Apresentadas como solução para a educação pública, aparecem articuladas aos pressupostos de eficiência, resultados, avaliação e competência (BARROSO, 2005a). Encontram-se inseridas no novo paradigma da gestão pública, como denomina Ball (2001), um pacote de reformas caracterizado pela ação mais focada nos resultados em termos de eficiência, eficácia e qualidade dos serviços. O Estado assume um papel regulador: embora a formulação das normas e leis continue centralizada, a gestão das políticas aparece descentralizada e o princípio da avaliação, como um aspecto fundamental para que o Estado exerça o controle dos resultados dessas mesmas políticas (BARROSO, 2005b).

As iniciativas da secretária de educação, Claudia Costin, que modificaram a política educacional municipal, tiveram como princípio a responsabilização, em que o desempenho dos alunos é visto como objetivo principal do trabalho da escola. 0 uso das avaliações externas é legitimado para medir a eficácia da escola e dos professores no cumprimento dessa tarefa. Além disso, de acordo com os resultados dos alunos, determinada escola ou professor poderia receber ou não incentivos, o que sinaliza a transferência do ônus pelos esforços de melhoria em direção à escola (BROOKE, 2012, p. 143).

Um sistema de responsabilização envolve três elementos: testes para os estudantes, divulgação pública do desempenho da escola, recompensas e sanções (FREITAS, 2012, p. 383). As recompensas e sanções compõem o caráter meritocrático do sistema, pois, na base da proposta política, está a igualdade de oportunidade e não de resultados. Assim, as oportunidades são dadas, mas o que faz a diferença é o esforço pessoal, o mérito de cada um. No entanto, como afirma Freitas (2012), nada é dito sobre a igualdade de condições no ponto de partida.

\section{O ciclo de políticas}

0 ciclo de políticas (BOWE; BALL; GOLD, 1992) é considerado uma abordagem produtiva para a análise das atuais políticas globais, pois ressalta a natureza complexa e controversa da política educacional e é um referencial teórico-analítico que não é estático, mas dinâmico e flexível. Mainardes (2006, p. 49) destaca que os autores acreditam na variedade de intenções e disputas que influenciam o processo político e, por isso, rejeitam os modelos de política educacional que separam as fases de formulação e implementação. Assim, Ball afirma (MAINARDES; MARCONDES, 2009, p. 35): "Quero rejeitar completamente a ideia de que as políticas sejam implementadas, pois isso sugere um processo linear pelo qual elas se movimentam em direção à prática de maneira direta [...] 0 processo de traduzir políticas em práticas é extremamente complexo".

Ball reconhece a importância da análise do Estado no ciclo de políticas, mas não se limita à perspectiva do controle estatal. Os processos macro e micro na análise de políticas são aspectos importantes do ciclo de políticas, pois é possível enfatizar os processos micropolíticos. 0 autor coloca-se contrário às abordagens estadocêntricas, que interpretam os textos e discursos sem considerar a interlocução com "o discurso pedagógico, com as demandas educacionais da sociedade mais ampla e as tradições curriculares das escolas e do meio educacional" (LOPES; MACED0, 2011, p. 253).

0 processo de formulação é considerado como um ciclo contínuo, no qual as políticas são formuladas e recriadas. A sua estrutura é composta por três contextos inter-relacionados, que "não têm uma dimensão temporal ou sequencial e não são etapas lineares" (MAINARDES, 2006, p. 50): os contextos de influência, o de produção de texto e o da prática. Posteriormente, Ball acrescenta dois contextos: o dos resultados/ efeitos e o da estratégia política. ${ }^{4}$

4 - Os contextos dos resultados e da estratégia política foram acrescentados por Ball ao referencial original em 1994, no livro Education 
Apesar da característica de continuidade do ciclo de políticas, o contexto de influência é concebido como onde "normalmente as políticas públicas são iniciadas e os discursos políticos são construídos" (MAINARDES, 2006, p. 51). É aqui que acontecem as ações de grupos de interesse para influenciar a definição das finalidades sociais e do que significa ser educado. É também onde os conceitos adquirem legitimidade e formam um discurso de base para a política.

Neste ponto, identificamos o discurso empregado pela secretária de educação, Claudia Costin, que objetivou legitimar a nova política educacional, por meio da defesa do "salto na qualidade da Educação no Rio de Janeiro" (SECRETARIA..., 2012). Tal discurso defıniu o que é a excelência na educação pública no ensino fundamental e na educação infantil, através da elaboração da referida política educacional e da avaliação de resultados.

Esse processo aparece acompanhado da criação das políticas educacionais de avaliação em larga escala, uma vez que essas são entendidas pelo Estado como uma estratégia capaz de medir os resultados das reformas adotadas pelos sistemas de ensino (COELHO, 2008; SOUZA, 2003). Políticas de avaliação não são restritas ao Brasil, pois cumprem uma agenda internacional, conforme é percebido através do Programa Internacional de Avaliação dos Estudantes (PISA), do qual fazem parte 65 países (BONAMINO; SOUZA, 2012). Dessa maneira, adquirem legitimidade e formam um discurso de base política, influenciando a formulação de políticas educacionais, como no caso aqui investigado.

Outro contexto, o da produção de texto, guarda estreita relação com o de influência, pois os textos políticos são vistos como a representação da política, mas podem ser lidos de diferentes formas, de acordo com as demandas da prática. Sendo assim, é no

reform: a critical and a post-structural approach. De acordo com 0 autor, eles deveriam ser incluídos no contexto da prática e da influência, respectivamente (BALL, 1994). contexto da produção de texto que este pode tomar várias formas, como "textos legais oficiais e textos políticos, comentários formais ou informais sobre os textos oficiais, vídeos etc" (MAINARDES, 2006, p. 52). Os textos políticos envolvidos nas presentes pesquisas são as Orientações curriculares de história e os Cadernos pedagógicos de história, formulados pela SME/RJ com a intenção de criar um currículo para esta disciplina e direcionar o trabalho do professor.

É no contexto da prática que acontecem as experiências com os textos políticos, é nele que "a política está sujeita à interpretação e à recriação e onde a política produz efeitos e consequências que podem representar mudanças e transformações significativas na política original" (BOWE; BALL; GOLD, 1992). 0 ponto crucial está no fato de que as políticas não são simplesmente implementadas; ao contrário, os sujeitos têm um papel ativo no processo reinterpretação das políticas educacionais.

As pesquisas apresentadas nesse artigo utilizaram o ciclo de políticas como referencial teórico-metodológico justamente porque, através dessa abordagem, a política educacional da SME/RJ foi analisada considerando a sua complexidade, sendo percebidos os novos sentidos que assumiu quando circulou nos diferentes contextos. A seguir, ambas as pesquisas serão apresentadas a partir de uma análise mais detalhada.

\section{Pesquisa 1 - O contexto da produção}

de texto: o trabalho da equipe de formuladores dos Cadernos pedagógicos de história e a política educacional da SME/RJ

0 principal objetivo da pesquisa 1 (SPINDOLA, 2014), intitulada $O$ contexto da produção do texto: a atuação dos professores formuladores dos cadernos pedagógicos de história da Secretaria Municipal de Educação do Rio de Janeiro, foi identificar de que forma, no momento de elaboração do material, os 
professores formuladores conseguiram integrar a política oficial e o que eles entenderam como necessário para o trabalho do professor na sala de aula.

A metodologia utilizada seguiu os princípios de um estudo qualitativo, utilizando a entrevista, realizada com a equipe que formulou os Cadernos pedagógicos de história da SME/ RJ, para a coleta de dados. Por sua vez, os documentos como as Orientações curriculares de história e os Cadernos pedagógicos de história auxiliaram a confirmação e validação das informações obtidas através das entrevistas.

A equipe formada para trabalhar na elaboração do material pedagógico esteve inserida em um contexto de mudança da proposta curricular. Os depoimentos foram recolhidos com a intenção de investigar como os professores elaboradores dos Cadernos pedagógicos de história lidaram com as orientações da nova política educacional da SME/RJ na produção do material, tendo em vista que muitos eram professores da rede.

No período em que as entrevistas foram feitas, a equipe dos formuladores dos Cadernos pedagógicos de história contava com cinco pessoas: o consultor, o coordenador, que também era o formulador do Caderno pedagógico de história do $6^{\circ}$ ano, e os outros três formuladores, do $7^{\circ}, 8^{\circ}$ e $9^{\circ}$ anos, que são professores regentes. Todos os entrevistados afirmaram que o convite para esse trabalho surgiu a partir do reconhecimento e consideração da qualidade de suas práticas pedagógicas.

Tabela 1- 0s professores integrantes da equipe

\begin{tabular}{|c|c|c|c|c|c|c|c|}
\hline Equipe & Idade & Graduação & Pós-graduação & $\begin{array}{l}\text { Tempo de } \\
\text { magistério }\end{array}$ & $\begin{array}{l}\text { Tempo na rede } \\
\text { municipal de } \\
\text { ensino }\end{array}$ & CRE & $\begin{array}{l}\text { Em quantas } \\
\text { escolas } \\
\text { trabalha na } \\
\text { rede }\end{array}$ \\
\hline Consultor & 69 anos & História & $\begin{array}{c}\text { Doutorado } \\
\text { em } \\
\text { História social }\end{array}$ & 51 anos & - & - & - \\
\hline $\begin{array}{l}\text { Coordenador e } \\
\text { formulador } 1 R\end{array}$ & 46 anos & Ciências sociais & $\begin{array}{l}\text { Especializaçã-o em } \\
\text { História e Pedagogia }\end{array}$ & 23 anos & 18 anos & $3^{a}$ & 01 \\
\hline Formulador $2 \mathrm{~A}$ & 27 anos & História & $\begin{array}{c}\text { Especialização } \\
\text { em } \\
\text { História da Ciência e da } \\
\text { Saúde }\end{array}$ & $\begin{array}{l}3 \text { anos e } \\
8 \text { meses }\end{array}$ & $\begin{array}{l}3 \text { anos e } \\
8 \text { meses }\end{array}$ & $2^{\mathrm{a}}$ & 01 \\
\hline Formulador $3 \mathrm{~J}$ & 57 anos & História & $\begin{array}{c}\text { Especialização } \\
\text { em } \\
\text { Ensino de História }\end{array}$ & 34 anos & 34 anos & $1^{\mathrm{a}}$ & 01 \\
\hline Formulador $4 \mathrm{~T}$ & 49 anos & História & $\begin{array}{l}\text { Especialização } \\
\text { em } \\
\text { História Social das } \\
\text { Ideias }\end{array}$ & 22 anos & 8 anos & $10^{a}$ & 01 \\
\hline
\end{tabular}

Fonte: Elaboração própria utilizando os dados da ficha de caracterização.

As entrevistas foram realizadas no edifício da prefeitura da cidade do Rio de Janeiro, localizado na Cidade Nova. Os entrevistados preencheram uma ficha de caracterização e responderam 21 perguntas. Apenas o coordenador respondeu outro questionário, com sete perguntas relacionadas ao trabalho desempenhado por ele. 1
A partir das entrevistas e dos documentos analisados, organizamos os seguintes eixos temáticos para orientar o trabalho:

- a equipe de elaboradores dos Cadernos pedagógicos de história;

- os materiais pedagógicos propostos pela SME/RJ; 
- o trabalho da equipe de elaboradores dos Cadernos pedagógicos de história;

- o olhar sobre os professores da rede municipal de ensino.

Os materiais analisados para a pesquisa foram as Orientações curriculares de história de 2009, 2012 e 2013 e os Cadernos pedagógicos de história do $6^{\circ}$ ao $9^{\circ}$ anos do $4^{\circ}$ bimestre de 2013, que foram elaborados no período da pesquisa.

As Orientações curriculares de história são interpretadas pelos formuladores como um currículo mínimo que deve ser seguido pelos professores. Todos os entrevistados comentaram de forma positiva as modificações feitas nas Orientações curriculares de 2012, além de afırmarem a importância desse documento no trabalho de elaboração dos Cadernos.

Os Cadernos pedagógicos de história fazem parte do material criado por essa gestão da SME/RJ. Eles passaram a ser distribuídos em 2010, inicialmente para as disciplinas de língua portuguesa, matemática e ciências. Posteriormente, as disciplinas de história e geografia foram contempladas. Os Cadernos pedagógicos de história do $6^{\circ}$ ao $9^{\circ}$ anos são produzidos bimestralmente, um para cada ano de ensino, totalizando dezesseis cadernos por ano. A partir de 2014, os Cadernos pedagógicos de história não foram mais distribuídos para as escolas. Estão disponíveis apenas na internet, no site da SME/RJ.

As questões elaboradas para as entrevistas foram pensadas para obter informações sobre o trabalho dos formuladores e sobre o próprio material pedagógico da SME/RJ.

Os entrevistados foram unânimes ao falar que o objetivo dos Cadernos pedagógicos é oferecer ao professor "um instrumento a mais" para o trabalho com as turmas. Nesse sentido, é importante destacar que a utilização desse material, segundo os professores elaboradores, é de livre escolha do professor da escola.

Esse material pedagógico, na visão do coordenador, permite a aproximação do conteúdo de história com o aluno e torna "mais palatável a matéria, mais agradável, mais fácil e mais significativa".

Também citaram como vantagens dos Cadernos pedagógicos o fato de serem um material que "tem a particularidade de estar mais próximo ao professor da rede", na medida em que foram feitas reuniões na SME/RJ com o propósito de promover melhorias. Além disso, os formuladores afirmaram que procuraram fazer um material que levasse em consideração questões ligadas à cidade do Rio de Janeiro, com linguagem mais apropriada aos alunos da rede.

No entanto, apesar de declararem que o objetivo dos Cadernos de história é de ser um instrumento a mais para o trabalho do professor, veremos, na pesquisa 2 (MORAES, 2012), que, em algumas escolas, isso não é vivenciado dessa maneira.

Sendo assim, encontramos nessa situação a interpretação da política da SME/RJ no contexto da escola. Segundo Ball (MAINARDES; MARCONDES, 2009, p. 305), “o processo de traduzir políticas em práticas é extremamente complexo; é uma alternação entre modalidades". Assim, na modalidade textual, na qual os Cadernos pedagógicos de história são elaborados, o objetivo do material é ser um instrumento de apoio pedagógico para o professor, que pode utilizá-lo de acordo com o seu planejamento. No entanto, quando a política é posta em prática, acontece uma modificação.

Com relação às condições de trabalho da equipe que formulou os Cadernos pedagógicos de história, foram abordadas questões relacionadas às dificuldades encontradas na elaboração do material, o espaço de participação dos formuladores na construção dos textos do Caderno e a influência da experiência da sala de aula no trabalho de formulação dos Cadernos pedagógicos.

Entre as dificuldades encontradas para a elaboração do material, a falta de tempo foi a mais comentada pelos integrantes da equipe durante as entrevistas. Segundo o consultor, o cronograma de trabalho do grupo estava sempre prejudicado pela da ausência de tempo, a qual 
diminuiu os momentos de estudo dos autores, dificultando o trabalho com novos conteúdos, com a atualização das Orientações curriculares ou elaboração de um texto.

Outras dificuldades foram descritas pelos autores, como: o trabalho de formatação e diagramação; a limitação do número de páginas, que impediu avançar um pouco mais em determinado conteúdo; a impressão dos Cadernos pedagógicos em preto e branco, que torna o material pouco atrativo para os alunos e também prejudica determinadas atividades como, por exemplo, aquelas com bandeiras; a escolha das imagens ilustrativas dos Cadernos, que devem ser somente as disponibilizadas na internet.

Sobre o espaço de participação dos profissionais envolvidos na elaboração dos Cadernos pedagógicos, a maioria dos formuladores afırmou a existência de liberdade no momento da construção dos textos do material. No entanto, na etapa de finalização, eles apontaram diversos casos de interferência que modificaram o texto produzido. Assim, os elaboradores contaram que: já foram chamados para dar explicações sobre o que escreveram; autores se retiraram do trabalho porque tiveram seus textos modificados sem concordar; os textos voltaram da revisão com modificações consideradas por eles inapropriadas; atividades foram retiradas sem a concordância do formulador.

Os integrantes da equipe dos Cadernos pedagógicos de história consideraram a existência de uma forte influência da experiência docente no trabalho de elaboração dos cadernos. Um exemplo disso surgiu na fala do formulador do material do $7^{\circ}$ ano, quando, no momento de elaboração do Caderno, procurou pensar em atividades que pudessem envolver os alunos: "Que o aluno consiga chegar a algum lugar depois de fazer aquela atividade, que aquela atividade não seja uma coisa maçante para ele. Que ele não faça com dor, que ele faça com o prazer de descobrir alguma coisa diferente." Foi nessa vivência, decorrente do contato com os alunos nas aulas ministradas, que os autores procuraram inspiração para elaborar o material da SME/RJ. Dessa forma, demonstraram que a relação com o aluno foi muito importante nesse trabalho, pois os textos e atividades elaborados ou escolhidos para constituir os cadernos, muitas vezes, foram aqueles que já haviam sido utilizados em sala de aula.

Mesmo diante de uma política curricular prescritiva e de uma política de metas e premiações, os elaboradores acreditavam que estavam produzindo um material que pudesse servir de suporte para o trabalho do professor.

Assim, concluímos que, dentro do contexto da produção de texto, houve a influência da prática pedagógica, caracterizada pelo funcionamento do trabalho da equipe e pelas ideias de cada professor elaborador sobre os Cadernos pedagógicos de história. Esses profissionais procuraram dar um sentido diferente ao material, com um direcionamento que foge da política de responsabilização e metas.

Isso se deu porque a equipe que formulou os Cadernos de história foi formada por professores da rede. Por estarem em sala de aula, estavam acostumados a interpretar e vivenciar a política de diversas formas. Quando passaram a atuar no contexto da produção dos Cadernos, levaram as suas experiências como docentes. Assim, afırmaram aproveitar os materiais de suas aulas, as experiências com os alunos, a preocupação com os demais colegas e os questionamentos de suas próprias práticas pedagógicas.

Portanto, através desta pesquisa, foi possível constatar que a elaboração dos Cadernos pedagógicos de história foi uma produção não de especialistas, mas sim de docentes que atuavam no contexto da prática. Talvez por serem professores de história, não abriram mão de seus princípios políticos ao se recusarem a seguir essa política de responsabilização e metas. Sendo assim, podemos afirmar que os professores elaboradores foram autores desse material pedagógico, pois trouxeram para o trabalho as suas práticas pedagógicas e ideais como educadores.

No entanto, mesmo considerando que a esfera do Estado não domina os sentidos 
atribuídos à política curricular, sabemos que o lugar ocupado pelo Estado traz fortes interferências na política, pois identificamos as limitações e impedimentos que são produzidos nessa esfera.

\section{Pesquisa 2- 0 contexto da prática: como os professores} reinterpretam o material pedagógico e a política educacional da SME/RJ

A dissertação intitulada $A$ educação parou": as orientações curriculares da SME/RJ reinterpretadas pelos professores de história no contexto da prática (MORAES, 2012) tinha como objetivo perceber quais sentidos do texto da política lhe são atribuídos pelos professores no contexto da prática, uma vez que a política está sujeita à novas interpretações e modificações de sentido, de acordo com a ação dos sujeitos. Outro objetivo desse trabalho também foi o de perceber como os professores compreendem a questão da autonomia docente em relação à política formulada pela Secretaria.

Para essa pesquisa, foram realizadas dez entrevistas com professores de história, que atuam no segundo segmento do ensino fundamental da rede municipal do Rio de Janeiro, no período de junho a novembro de 2013. A princípio, essas ocorreriam nas unidades escolares da $2^{\text {a }}$ Coordenadoria Regional de Ensino (2 ${ }^{\text {a }} \mathrm{CRE}$ ). Essa região foi escolhida porque abrange bairros das zonas sul e norte da cidade, apresentando escolas com realidades diversas. ${ }^{5}$

Porém, uma greve dos profissionais da educação que eclodiu durante o segundo semestre de 2013 impossibilitou a realização das entrevistas nas escolas. ${ }^{6}$ Apenas três delas ocorreram nas unidades escolares: a primeira antes da greve, e duas após o término da paralisação. Sete entrevistas foram feitas ou agendadas em atividades ligadas à greve, como assembleias e atos. Abaixo encontra-se uma tabela com os dados sobre os sujeitos entrevistados.

Tabela 2- Os professores entrevistados

\begin{tabular}{|c|c|c|c|c|c|c|c|}
\hline Professores & Sexo & Idade & $\begin{array}{l}\text { Data de } \\
\text { graduação }\end{array}$ & Pós-graduação & $\begin{array}{l}\text { Tempo de } \\
\text { atuação }\end{array}$ & Tempo na rede & CRE \\
\hline C. & Feminino & $40-50$ & 1990 & $\begin{array}{l}\text { Doutorado } \\
\text { História Social }\end{array}$ & 25 anos & 25 anos & $2^{\mathrm{a}}$ \\
\hline $\mathrm{L}$. & Feminino & $30-40$ & 1992 & $\begin{array}{c}\text { Lato Sensu } \\
\text { Ensino de História }\end{array}$ & 10 anos & 3 anos & $3^{\mathrm{a}}$ \\
\hline E. & Feminino & $30-40$ & 2006 & $\begin{array}{c}\text { Mestrado } \\
\text { História Social }\end{array}$ & 6 anos & 3 anos & $5^{a}$ \\
\hline $\mathrm{T}$. & Feminino & $20-30$ & 2006 & $\begin{array}{c}\text { Mestrado } \\
\text { Ciência da Informação Lato Sensu } \\
\text { História do Brasil }\end{array}$ & 3 anos & 3 anos & $7^{\mathrm{a}}$ \\
\hline J. & Feminino & $40-50$ & 1988 & $\begin{array}{c}\text { Doutorado } \\
\text { Serviço Social }\end{array}$ & 26 anos & 18 anos & $2^{\mathrm{a}}$ \\
\hline S. & Masculino & $20-30$ & 2010 & Não possui & 2 anos & 2 anos & $6^{\mathrm{a}}$ \\
\hline V. & Feminino & $30-40$ & 2002 & $\begin{array}{c}\text { Mestrado } \\
\text { História Social }\end{array}$ & 12 anos & 5 anos & $8^{a}$ \\
\hline R. & Feminino & $50-60$ & 1981 & Lato Sensu Psicopedagogia & 23 anos & 11 anos & $4^{\mathrm{a}}$ \\
\hline M. & Masculino & $40-50$ & 1994 & $\begin{array}{c}\text { Mestrado } \\
\text { Bens Culturais e Projetos Sociais }\end{array}$ & 17 anos & 17 anos & $2^{\mathrm{a}}$ \\
\hline B. & Masculino & $50-60$ & 1986 & Não possui & 23 anos & 22 anos & $2^{\mathrm{a}}$ \\
\hline
\end{tabular}

5- A ficha de caracterização completa e os questionários das entrevistas estão disponíveis na pesquisa 2 (MORAES, 2012).

6- Essa greve chegou a atingir um índice de $90 \%$ de paralisação, segundo as estimativas do Sindicado Estadual dos Profissionais da Educação do Rio de Janeiro (SEPE). Disponível em: <http://www.seperj.org.br/ver_noticia. php?cod_noticia=4352>. Acesso em: 15 ago 2013. 
Os entrevistados eram de diferentes faixas etárias. A experiência profissional e o tempo de atuação na rede também variavam. Oito entre dez professores entrevistados possuíam cursos de pós-graduação. Outro dado fundamental para a análise foi a diversidade de coordenadorias às quais pertenciam. Apenas quatro docentes estavam lotados na $2^{\text {a }}$ CRE. Desses, três foram entrevistados no período fora da greve, seguindo o cronograma inicial da pesquisa. Entre os professores entrevistados durante a greve, apenas um era dessa coordenadoria. Como as escolas permaneceram fechadas durante a paralisação, foi necessário buscar docentes que aderiram ao movimento e realizar mudanças no cronograma e na metodologia da pesquisa. ${ }^{7}$

Essa mudança metodológica foi realizada não apenas por uma questão prática, mas também porque a greve acabou se transformando em um indicador a mais para a pesquisa. Apesar de não haver nenhuma questão específica no roteiro de entrevista, os professores trouxeram esse assunto e percebem a paralisação como uma reação da categoria à reforma empreendida pela SME/RJ, uma vez que apresentaram discursos críticos às mudanças curriculares, à avaliação unificada e à política de metas.

Entretanto, além de toda a problemática ocasionada pela greve, ainda foi necessário investigar outros aspectos dos depoimentos dos professores para uma análise mais aprofundada sobre os sentidos atribuídos à política na prática. Os depoimentos sobre os usos do currículo oficial foram fundamentais nesse sentido.

Os entrevistados afirmaram que a lista de conteúdos presente nas Orientações curriculares não é diferente da que tradicionalmente compõe a disciplina no ensino fundamental, segundo a lógica da história integrada, em que a história do Brasil aparece vinculada à história mundial e principalmente da Europa. Segundo Bittencourt (2011, p. 157), essa abordagem apresenta algumas inovações, mas mantém o criticado

7- A ficha de caracterização e os questionários das entrevistas estão disponíveis na pesquisa 1 (SPINDOLA, 2014). pressuposto eurocêntrico, com uma diminuição acentuada dos conteúdos de história nacional, da América e África.

Foi constatado que os professores não consideram as Orientações curriculares como um modelo de currículo fechado em seu planejamento, já que disseram fazer adaptações e não seguir essa diretriz integralmente. Afirmaram que não é possível cumprir toda a lista de conteúdos, seja por falta de tempo, ou seja porque selecionam os conteúdos mais significativos para o local onde atuam.

Em relação às listas de habilidades e de objetivos presentes nas Orientações, os entrevistados afırmaram que essas dificilmente são introduzidas em seus planejamentos, porque elas não consideram as particularidades das escolas e as diferenças encontradas na rede. Verificou-se, portanto, que os próprios professores estabelecem habilidades a desenvolver e objetivos a alcançar.

Sobre os Cadernos pedagógicos, foi observado que são utilizados com frequência por cinco dos professores. Três outros entrevistados relataram que o material não satisfaz seus objetivos e, por essa razão, é utilizado apenas quando encontram uma atividade que consideram interessante. Os dois professores que não usam os Cadernos em suas aulas assim o fazem porque assumiram uma postura crítica em relação à reforma iniciada pela Secretaria.

Sobre as vantagens em utilizar os Cadernos pedagógicos, foi dito que: eles "apresentam links para pesquisa na internet", "possuem textos curtos", "possuem letra grande", "utilizam joguinhos". Entretanto, nove entre dez professores pesquisados fizeram severas críticas ao material. Esses foram descritos como "fracos", "ruins", "precários" e "mal feitos". Afirmaram que apresentam "erros de português", "erros de conteúdo", "erros conceituais" e "erros de revisão". Deixam a desejar porque são "muito simplificados", "reduzidos" e "resumidos demais". 0 fato de serem impressos em preto e branco também foi citado como um problema do material, conforme foi mencionado na pesquisa 1 (SPINDOLA, 2014). 
Os entrevistados também afırmaram que os conteúdos aparecem descontextualizados do tempo presente, atrelados a um saber histórico tradicional e com víeis pouco crítico. Esse modelo seria insuficiente para a formação intelectual e o desenvolvimento do espírito crítico nos alunos (BITTENCOURT, 2011, p. 230).

A pesquisa aqui apresentada concorda com estudos como o de Leite (2012) e Marcondes (2013), que apresentaram como resultado que os professores consideram os materiais apostilados insuficientes, pois enfatizam atividades de memorização, costumam vir atrelados às avaliações em larga escala e se concentram no formato múltipla escolha.

Apesar dessas críticas, três professores afırmaram que os Cadernos são adaptados às precárias condições da rede municipal, em que muitos estudantes apresentam grave dificuldade de leitura e interpretação de textos. Um professor disse que os textos curtos dos Cadernos pedagógicos agradam aos estudantes. Outra professora sugeriu que os alunos realizam as atividades dos Cadernos com mais autonomia e, por isso, esse material se adapta melhor a salas de aula superlotadas.

Nessa pesquisa, concluímos que os professores entrevistados não se limitam ao currículo oficial proposto pela SME/RJ. 0 currículo planejado e trabalhado na sala de aula inclui outras demandas presentes no contexto da prática, consideradas a partir do interesse demonstrado pelos estudantes, em função de conteúdos e conceitos aprendidos nas séries anteriores e das referências socioculturais trazidas por eles. Entre os materiais didáticos empregados, sete professores preferem utilizar o livro didático em vez dos Cadernos pedagógicos, quando o primeiro se encontra disponível nas escolas. Também disseram que costumam usar vídeos, jornais, internet, música e outros materiais didáticos.

Entretanto, alguns professores relataram que encontram obstáculos para realizar a atividade de seleção e planejamento devido à precariedade da profissão docente (trabalham em muitas escolas), às péssimas condições encontradas nas unidades escolares (salas de aula lotadas de alunos, falta de equipe de apoio nas escolas, más condições físicas dos prédios) ou a problemas de violência nas comunidades próximas às escolas.

Apesar desses obstáculos, constatou-se que os professores entrevistados possuem autonomia para realizar a seleção curricular. Entretanto, uma professora relatou que a gestão da escola onde atua exige o uso dos Cadernos pedagógicos pelos docentes. Outras duas professoras afırmaram que utilizam esse material porque temem sofrer algum tipo de retaliação da SME/RJ ou mesmo dos responsáveis dos alunos. Os outros professores relataram nunca ter passado por situação como essa, mas reconheceram que a imposição por parte da gestão ocorre em alguns casos, principalmente com as disciplinas língua portuguesa, matemática e ciências, quando as atividades presentes funcionam como treinamento para as avaliações bimestrais. $^{8}$

Segundo Hypolito e Ivo (2013), muito embora se tenha um discurso de que o currículo não seja prescritivo, as avaliações padronizadas assumem o caráter de prescrição curricular. Essa situação foi relatada pelos entrevistados, uma vez que alguns gestores de unidades escolares entendem que o currículo proposto pela SME/ $\mathrm{RJ}$ funcionaria como um manual que prepara os alunos para obter melhores resultados nas avaliações unificadas da rede municipal.

A ausência de prova unificada da disciplina história foi, portanto, interpretada de forma positiva pelos professores entrevistados, porque garante mais autonomia para a prática pedagógica. Giroux (1997, p. 160) defende que a aquisição de pacotes pedagógicos implica a "redução da autonomia do professor com respeito ao desenvolvimento e planejamento curricular e o julgamento e implementação de instrução em sala

8- Apesar de não haver nenhuma diretriz da Secretaria que torne esse material obrigatório, a gestão das escolas precisa assinar o "Termo de compromisso de desempenho escolar", em que se compromete a melhorar 0 ensino, com base nas metas estabelecidas pela SME/RJ (LEITE, 2012, p. 79). 
de aula”. Entretanto, no caso aqui investigado, não é possível reduzir os professores à função de técnicos aplicadores de diretrizes produzidas fora do contexto escolar, já que constatamos que são sujeitos ativos nesse processo.

Concluímos que outros sentidos foram atribuídos ao currículo oficial no contexto da prática. Esses são construídos de acordo com as particularidades presentes em cada unidade escolar. As relações estabelecidas entre professores, estudantes e as disputas presentes entre eles e a gestão das unidades escolares interfere na reinterpretação da política curricular e na resignifıcação do material curricular produzido pela SME/RJ.

Porém, a política da SME/RJ foi descrita pelos entrevistados como limitadora da autonomia docente (CONTRERAS, 2012) e da autonomia da escola (BARROSO, 1996), porque aumenta o controle da Secretaria de Educação sobre a escola e os sujeitos que nela atuam, principalmente por conta da relação entre currículo, avaliação, estabelecimento de metas e responsabilização. A política de bonificação concedida às escolas não foi defendida por nenhum dos entrevistados, porque essa não seria capaz de garantir a qualidade da educação pública, e provocaria disputas entre gestão e professores, ou mesmo entre professores, quando as questões burocráticas ou a busca pela bonificação superam as expectativas em relação à aprendizagem dos estudantes.

No caso específico dos professores de história, foi relatado nas entrevistas que a aprovação dos alunos em todas as disciplinas, mesmo naquelas que não realizam as avaliações unificadas, é supervalorizada como uma estratégia para que a escola atinja a meta estabelecida.

Sendo assim, a análise dos depoimentos sugere que a reforma curricular da SME/RJ, atrelada à reforma da política educacional de modo mais amplo, trouxe como consequência a limitação da autonomia docente e da escola. Os entrevistados citaram outros fatores que provocam essa limitação: a falta de diálogo com a Secretaria; a imposição de projetos e a desconsideração de projetos criados na escola; a interferência de gestores na aprovação e reprovação de alunos; e o estabelecimento de datas fixas para as avaliações da rede, sem levar em conta o calendário interno das escolas.

\section{Considerações finais}

0 contexto da educação municipal pesquisado era caracterizado pela busca permanente da qualidade e excelência do ensino nas escolas e esteve atrelado à atualização de Orientações curriculares, lista de descritores (para as disciplinas língua portuguesa, matemática e ciências) e elaboração de Cadernos pedagógicos, que compõem o currículo oficial da SME/RJ. Discutimos anteriormente que essas iniciativas tiveram a intenção de oferecer orientações prescritivas para o trabalho dos professores, objetivando melhores resultados dos alunos nas avaliações unificadas da rede ou a aprovação na disciplina história para conseguir um bom fluxo escolar.

Através da análise das entrevistas da pesquisa 1 (SPINDOLA, 2014), foi possível perceber que os professores elaboradores acreditavam que estavam produzindo um material útil; no entanto, muitas vezes essa ideia não foi compartilhada pelos professores da rede. De acordo com a pesquisa 2 (MORAES, 2012), os professores criticaram o material, apenas metade dos entrevistados disseram que o utilizam com frequência, e mesmo estes consideram que o ele possui inúmeros problemas.

Dessa forma, podemos identificar a complexidade das esferas da política. No contexto da produção de texto, as ações dos elaboradores estavam voltadas ao preparo de um material de qualidade e utilidade para o professor. A SME/ RJ deveria oferecer as melhores condições de trabalho para a equipe formular o material. Todavia, os entrevistados mencionaram diversas dificuldades que interferiram na produção dos Cadernos pedagógicos de história, o que provavelmente repercutiu negativamente na qualidade do material. 
Já no contexto da prática, a maioria dos professores entrevistados afirmou que o material não é satisfatório. Quando criticaram ou afirmaram que os Cadernos pedagógicos de história são adaptados às péssimas condições de ensino oferecidas pela rede, evidenciaram uma contradição: a SME/RJ tinha como objetivo melhorar a qualidade da educação, mas ofereceu para professores e alunos um material pedagógico considerado de má qualidade ou que pode ser adequado às precárias condições atuais.

Como afirmam Lopes e Macedo (2011), as políticas são textos complexos e decodificados de forma complexa em meio a lutas, negociações, acordos e alianças, espelhando a própria historicidade. Ao longo deste trabalho, atestamos que o sentido atribuído pela SME/RJ aos textos políticos não é o mesmo da equipe que formula o material didático, assim como este adquire outros sentidos para os professores que o utilizam. Mesmo que a Secretaria tente direcionar as leituras, esse controle é sempre parcial, "seja pela própria lógica da política, seja pelas características próprias do fato de se tratar de um texto" (LOPES; MACEDO, 2011, p. 259).

A equipe dos Cadernos pedagógicos de história enfatizou nas entrevistas a defesa da autonomia do professor na utilização do Caderno e que a intenção do grupo não era produzir um material para substituir o livro didático. Tais afırmativas mostram mais uma vez a ação dos elaboradores para formular um material que pudesse contribuir com o trabalho do professor, sem interferir no seu planejamento.

De acordo com a pesquisa 2 (MORAES, 2012), percebe-se que os professores mantêm autonomia para a seleção dos conteúdos trabalhados, para o estabelecimento de objetivos e habilidades a serem alcançados, de acordo com as condições encontradas na realidade onde atuam. Também possuem autonomia para a escolha de materiais didáticos, embora tenham relatado que, em alguns casos, a gestão da escola interferiu na escolha do material.

A partir das entrevistas da pesquisa 1 (SPINDOLA, 2014), entendemos que a visão da equipe sobre os Cadernos pedagógicos de história é diferente da visão da SME/RJ. Mesmo com a afirmação, por parte da secretária de educação, de que os Cadernos são um material de apoio, compreendemos, através das informações coletadas e analisadas na pesquisa 2 (MORAES, 2012), que esse material está inserido em uma reforma curricular que interfere na autonomia pedagógica do professor e na autonomia da escola em diversos sentidos. 0 currículo oficial da SME/ RJ, portanto, está inserido em uma lógica que favorece o desempenho, a eficácia, a premiação.

A maioria dos professores elaboradores demonstrou ter conhecimento da política educacional posta em prática desde 2009, assim como os professores presentes no contexto da prática. Nas entrevistas com os professores elaboradores, identificamos que a atuação da equipe era justamente para produzir um material que oferecesse mais autonomia ao professor. Sabemos, entretanto, que a política é recontextualizada por diversos sujeitos e, assim, em alguns casos, os gestores das escolas interferiram na escolha do material didático e exigiram seu uso, situação que foi mais frequente nas disciplinas que realizam a avaliação bimestral da rede municipal, mas que também foi vivenciada por uma professora de história entrevistada.

0 propósito da equipe dos professores elaboradores ficou restrito ao contexto de produção dos Cadernos, pois, no contexto da prática, muitos professores atribuíram um sentido negativo ao material, relacionado ao treinamento para as avaliações em virtude da política de metas. As Orientações curriculares e principalmente os Cadernos pedagógicos são compreendidos pelos entrevistados como parte da reforma educacional empreendida pela SME/ RJ, uma vez que a aprovação dos estudantes, mesmo na disciplina história, passou a ser supervalorizada diante da possibilidade de bonificação, em prejuízo à aprendizagem. A crítica ao material pedagógico, portanto, não aparece isolada da construção de novos sentidos da política educacional da SME/RJ no contexto da prática. 


\section{Referências}

ADRIĨ̃), Theresa et al. Uma modalidade peculiar de privatização da educação pública: a aquisição de sistemas de ensino por municípios paulistas. Educação \& Sociedade, Campinas, v. 30, n. 108, p. 799-818, out. 2009.

BALDIN, Nelma; MUNHOZ, Elzira. Snowball (bola de neve): uma técnica metodológica para pesquisa em educação ambiental comunitária. In: CONGRESSO NACIONAL DE EDUCAÇÃO - EDUCERE, 10. Curitiba, 2011. Anais... Curitiba: PUC, 2011. Disponível em: <http://educere.bruc.com.br/CD2011/pdf/4398_2342.pdf>. Acesso em: 20 ago. 2013.

BALL, Stephen. Diretrizes políticas globais e relações políticas locais em educação. Currículo sem Fronteiras, v. 1384, p. 99-116, 2001.

BALL, Stephen. Educational reform: a critical and post-structural approach. Buckingham: Open University Press, 1994.

BARROSO, João. 0 estudo da autonomia da escola: da autonomia decretada à autonomia construída. In: BARROSO, João (Org.). 0 estudo da escola. Porto: Ed. Porto, 1996. p. 167-189.

BARROSO, João. Políticas educativas e organização escolar. Lisboa: Universidade Aberta, 2005a.

BARROSO, João. 0 Estado, a educação e a regulação das políticas públicas. Educação \& Sociedade. Campinas, v. 26, n. 92 (Especial), p. 725-75, out, 2005b.

BITTENCOURT, Circe Maria Fernandes. Ensino de história: fundamentos e métodos. 4. ed. São Paulo: Cortez, 2011.

BONAMINO, Alícia; SOUSA, Sandra Zákia. Três gerações de avaliação da educação básica no Brasil: interfaces com o currículo da/ na escola. Educação e Pesquisa, São Paulo, v. 38, n. 2, p. 373-388, abr./jun. 2012.

BOWE, Richard; BALL, Stephen; GOLD, Anne. Reforming education e changing schools: case studies in policy sociology. London: Routledge, 1992.

BROOKE, Nigel. Uma nação em risco. In: BR00KE, Nigel (Org.). Marcos históricos na reforma da educação. Belo Horizonte: Fino Traço, 2012. p.143-148.

COELHO, Maria Inês de Matos. Vinte anos de avaliação da educação básica no Brasil: aprendizagens e desafios. Ensaio, Rio de Janeiro, v. 16, n. 59, p. 229-258, abr./jun. 2008.

CONTRERAS, José. A autonomia de professores. 2. ed. São Paulo: Cortez, 2012.

COSTIN, Claudia. Aula inaugural: avanços e desafios da educação no Rio de Janeiro. Disponível em: <http://www.youtube.com/ watch?v=VI-3-Zqcg1A>. Acesso em: 10 mai. 2013.

FREITAS, Luiz Carlos de. Os reformadores empresariais da educação: da desmoralização do magistério à destruição do sistema público de educação. Educação \& Sociedade, Campinas, v. 33, n. 119, p. 379-404, abr/jun, 2012.

GIROUX, Henry. Os professores como intelectuais: rumo a uma pedagogia crítica da aprendizagem. Porto Alegre: Artes Médicas, 1997.

HYPOLITO, Álvaro Moreira; IVO, Andressa Aita. Políticas curriculares e sistemas de avaliação: efeitos sobre o currículo. e-Curriculum, São Paulo, v. 11, n. 2, p. 376-392, ago. 2013.

LEITE, Vânia. A atuação da coordenação pedagógica em conjunto com os professores no processo de recontextualização da política oficial no primeiro segmento do ensino fundamental do Rio de Janeiro. Tese (Doutorado) - Pontifícia Universidade Católica do Rio de Janeiro, Rio de Janeiro, 2012.

LOPES, Alice Casimiro; MACEDO, Elizabeth. Contribuições de Stephen Ball para o estudo de políticas de currículo. In: BALL, Stephen; MAINARDES, Jefferson (Org.). Políticas educacionais: questões e dilemas. São Paulo: Cortez, 2011. p.249-283.

MAINARDES, Jefferson. Abordagem do ciclo de políticas: uma contribuição para a análise de políticas educacionais. Educação \& Sociedade, Campinas, v. 27, n. 94, p. 47-69, jan./abr. 2006. 
MAINARDES, Jefferson; MARCONDES, Maria Inês. Entrevista com Stephen J. Ball: um diálogo sobre justiça social, pesquisa e política educacional. Educação \& Sociedade, Campinas, v. 30, n. 106, p. 303-318, jan./abr. 2009.

MARCONDES, Maria Inês. Professores, currículo e didática: desafios frente às novas políticas de sistemas apostilados na rede pública. In: FAVACHO, Marcio Pincanço; PACHECO, José Augusto; SALES, Shirlei Resende. Currículo, conhecimento e avaliação: divergências e tensões. Curitiba: CRV, 2013. p.137-151.

MINAYO, Maria Cecília de Souza. 0 desafio da pesquisa social. In: MINAYO, Maria Cecília de Souza et al. Pesquisa social: teoria, método e criatividade. 27. ed. Petrópolis: Vozes, 2008. p.9-29.

MORAES, Caroline A. F. da Luz. "A educação parou”: as orientações curriculares da SME/RJ reinterpretadas pelos professores de história no contexto da prática. Dissertação (Mestrado) - Pontifícia Universidade Católica do Rio de Janeiro, Rio de Janeiro, 2012.

SECRETARIA MUNICIPAL DE EDUCAÇÃO DO RIO DE JANEIRO. Cadernos pedagógicos da rede municipal. Disponível em: <http://www.rio.r.j.gov.br/web/sme/exibeconteudo?id=2696665>. Acesso em 07 dez. 2013.

SECRETARIA MUNICIPAL DE EDUCAÇÃO DO RIO DE JANEIRO. Conheça a Secretaria. Disponível em: <http://www.rio.rj.gov.br/ web/sme/exibeconteudo?article-id=94101>. Acesso em: 9 out. 2012.

SECRETARIA MUNICIPAL DE EDUCAÇÃO DO RIO DE JANEIRO. Material pedagógico. Disponível em: <http://www.rio.rj.gov.br/ web/sme/material-pedagogico>. Acesso em: 16 dez. 2013.

SECRETARIA MUNICIPAL DE EDUCAÇÃO DO RIO DE JANEIRO. Orientações curriculares: áreas específicas. Rio de Janeiro: SME, 2009. p. 154-226.

SECRETARIA MUNICIPAL DE EDUCAÇÃO DO RIO DE JANEIRO. Orientações curriculares: áreas específicas. Rio de Janeiro: SME, 2012. SECRETARIA MUNICIPAL DE EDUCAÇÃO DO RIO DE JANEIRO. Orientações curriculares: áreas específicas. Rio de Janeiro: SME, 2013.

SOUZA, Sandra. Possíveis impactos das políticas de avaliação no currículo escolar. Cadernos de Pesquisa, São Paulo, n. 119, p. 175-190, jul, 2003.

SPINDOLA, Luisa da S. Kaufman. 0 contexto da produção do texto: a atuação dos professores formuladores dos cadernos pedagógicos de história da Secretaria Municipal de Educação do Rio de Janeiro. Dissertação (Mestrado) - Pontifícia Universidade Católica do Rio de Janeiro, Rio de Janeiro, 2014.

Recebido em: 26.04.2015

Aprovado em: 15.03.2016

Caroline da Luz Moraes é mestre em educação pela Pontifícia Universidade Católica do Rio de Janeiro (PUC-RJ) e professora de história da rede municipal de Duque de Caxias, Rio de Janeiro.

Luisa Kaufman Spindola é mestre em educação pela Pontifícia Universidade Católica do Rio de Janeiro (PUC-RJ). 